\title{
THE DARK ADAPTATION OF COAL MINERS SUFFERING FROM NYSTAGMUS
}

\author{
BY \\ Forbes W. SHARPLEY \\ FROM THE NUFFIELD LABORATORY OF \\ OPHTHALMOLOGY, OXFORD
}

\section{Introduction}

It has long been known that miners suffering from nystagmus commonly exhibit signs of poor dark adaptation. ${ }^{2} 2345$ Some investigations of the prevalence and degree of night blindness have been made in the past, but in most of these the experimental conditions either do not appear to have been adequately controlled or else are not fully stated. For these' and other reasons it was decided to make dark adaptation tests under strictly controlled conditions, not only on men who were obviously suffering from the disease, but also on miners who were not victims and on completely normal non-miners.

\section{Type of test}

It was decided that the simplest possible test giving consistent results should be used, since men suffering from nystagmus are notoriously apt to be nervous and often somewhat dull mentally. For this reason no disturbing initial bright light adaptation was used and only the final rod threshold measured. Fortuitous initial variations in the state of light adaptation due, for example, to entering the dark-room from out-of-doors daylight, were reduced to a minimum by the practice of causing the subject to remain in the room illuminated solely by ordinary artificial light for 15 minutes before completely darkening the room. Repeated tests on control subjects showed that any residual effect on the final rod threshold was entirely negligible. The same subject tested by day and by night gave consistent results.

A further reason for not placing emphasis on any measurements other than the final rod threshold was that it is known that even for normal subjects the course or rate of adaptation varies considerably in different individuals, especially in the early stages of dark adaptation. When a single figure is used for assessing visual performance in the dark, measurements are therefore best made in conditions approaching complete dark adaptation. It is true that a common complaint amongst nystagmic miners is that it takes them longer than usual " to get accustomed to the dark." They do not so frequently complain of inability to see in a dim light 
after sufficient time for dark adaptation. Hence, it would have been of interest to measure the rate at which they dark adapt, but simplicity and avoidance of discomfort to the subject were considered of more importance in deciding on the procedure of the test. On the other hand, every effort was made to measure the final rod threshold as precisely as conditions would allow.

\section{Instrument and method}

The dark adaptometer used was a Hecht-Shlaer Model No. 3. This is a portable instrument using a fixation point and arranged to present the test light in short flashes (of one-fifth second). The area of the retina tested is a disc of $3^{\circ}$ extent whose centre is situated $7^{\circ}$ above the fovea. The test is binocular and the natural pupils are used. The distance between the eye and the test field is approximately 10 inches. Filters are incorporated in the instrument which pass only extreme violet light to the test field. The instrument is so designed that the reading of the brightness scale can be calibrated from time to time in a simple manner by means of a self-contained standard lamp and photometer. Thus, ageing of the working lamp could be compensated for.

The approximate value of the light threshold of the fully dark adapted eye was first found by giving each subject a few flashes of the test light covering a range of brightness from that clearly visible to that quite invisible. This procedure, incidentally, gave the subject some desirable initial practice. Within the ascertained range limits a series of flashes was then given in random order of brightness. After a short interval this series was repeated four times. The final value of the threshold was computed by a statistical method on the basis of all five series, involving altogether some 30 to 45 exposures. All the subject had to do was to say whether or not he had seen each flash. The actual test occupied less than 10 minutes, apart from the initial period of dark adaptation, which was usually 40 minutes, and never less than 35 minutes, and itself followed the 15 minute period in a dimly lighted room, as mentioned above.

The dark adaptometer used was calibrated in log micro-microlamberts as brightness units $(\log \mu \mu l)$. It is known that there is a range of uncertain seeing near the threshold of about one log unit. Within this range the flash will sometimes be seen and sometimes not. The chief cause of the variation in visibility has been shown to be random physical fluctuations in the light source caused by the quantum nature of light. ${ }^{6}$ Hence, the necessity for using a considerable number of flashes. From a study of the "scatter" of the results obtained on testing 125 
normal subjects (non-miners) it was found that the value of the threshold computed from the results of the five series of exposures could be relied on to give a precision of $0.1 \log \mu \mu l$ (computed on the basis of three times standard deviation). The first series of exposures used alone would give a precision of about $0225 \log \mu \mu 1$. This is substantiated by the results of other workers.

\section{Normals}

A group of 125 subjects (non-miners) used as normals were volunteers of both sexes and various ages. They were not chosen strictly at random. While no conscious choice was exercised in selection, a certain amount of unavoidable selection was introduced by the difficulty of obtaining the necessary volunteers with the time to spare, especially in the higher age groups. It was a matter of accepting those who could come for test, provided they showed no serious visual abnormalities, other than moderate errors of refraction. The majority of the subjects had no scientific training, though a proportion, especially in the younger age groups, was made up of medical students or medical or nursing staff.

The subjects were divided into age groups, each group covering a range of 10 years. A summary of the dark-adaptation measurements is given in Table I.

TABLE I. Normals (non-miners)

Final rod thresholds when completely dark adapted.

\begin{tabular}{l|c|c|c|c|c|c}
\hline Age group (years) & $10 / 20$ & $20 / 30$ & $30 / 40$ & $40 / 50$ & $50 / 60$ & $60 / 70$ \\
Number of subjects & 27 & 25 & 31 & 26 & 12 & 4 \\
$\begin{array}{c}\text { Average value of threshold } \\
(\log \mu \mu 1)\end{array}$ & $>1 \cdot 75$ & 1.86 & 1.94 & $2 \cdot 07$ & 2.15 & 2.23 \\
$\begin{array}{c}\text { Standard deviation of } \\
\text { threshold values }\end{array}$ & - & 0.23 & 0.20 & 0.32 & 0.27 & 0.32 \\
\hline
\end{tabular}

In the case of the $10 / 20$ years age group it was found that a number of subjects showed a threshold below the lowest value measurable with the adaptometer used. For this reason and because no miners in this age group were examined, the results for this group have not been so far utilised.

The continuous increase in the threshold value with age is very evident and confirms that found by other workers. 
In order to obtain some estimate of the variability of the threshold for the same subject as measured on different occasions, one subject was given eight complete repeat tests at separate sittings at intervals of a week or two. The results are given in full in Table II, which shows not only the threshold as computed on the basis of all five series of exposures of the test light, but also that based on the first series, first two series, and first three series alone. The decreasing scatter of the computed threshold values for increasing number of exposures of the test light is of interest. Repeated tests on several other subjects (not here recorded) show similar characteristics in general.

TABLE II. Normal (non-miner)

Final rod threshold when completely dark adapted.

Repeated tests on one subject.

\begin{tabular}{|c|c|c|c|c|}
\hline \multirow[b]{2}{*}{ Test No. } & \multicolumn{4}{|c|}{ Threshold in $\log \mu \mu \mathrm{l}$} \\
\hline & $\begin{array}{c}\text { 1st exposure } \\
\text { series alone }\end{array}$ & $\begin{array}{l}\text { 1st two } \\
\text { series alone }\end{array}$ & $\begin{array}{l}\text { 1st three } \\
\text { series alone }\end{array}$ & $\begin{array}{l}\text { All five } \\
\text { series }\end{array}$ \\
\hline 1 & $2 \cdot 35$ & $2 \cdot 35$ & $2: 29$ & $2 \cdot 27$ \\
\hline 2 & $2: 25$ & $2 \cdot 30$ & $2: 29$ & $2 \cdot 29$ \\
\hline 3 & 2.05 & 2.20 & 219 & $2 \cdot 21$ \\
\hline 4 & $2 \cdot 25$ & $2: 20$ & $2 \cdot 25$ & $2 \cdot 25$ \\
\hline 5 & $2 \cdot 25$ & $2 \cdot 30$ & $2 \cdot 32$ & $2 \cdot 31$ \\
\hline 6 & $2 \cdot 10$ & $2 \cdot 20$ & $2 \cdot 21$ & $2 \cdot 17$ \\
\hline 7 & $2: 25$ & $2 \cdot 25$ & $2 \cdot 25$ & $2 \cdot 27$ \\
\hline 8 & $2 \cdot 35$ & $2 \cdot 25$ & $2 \cdot 29$ & $2 \cdot 29$ \\
\hline Mean & $2 \cdot 23$ & $2 \cdot 26$ & $2: 26$ & $2 \cdot 26$ \\
\hline S.D. & 0.107 & 0.056 & 0.045 & 0.047 \\
\hline
\end{tabular}

Confining attention to the values in the last column for all five series of exposures (which are comparable with all the other results in this report) it will be seen that the variation of threshold as found at different times is not large. Part of the difference is 
no doubt real and due to physiological factors. The same factors may be expected to affect the results of all subjects tested, to an extent of the order shown for the same subject on different occasions. Compared with the actual differences between individuals (as shown in Table I above for normals and in Table III for miners) this variation is seen to be in general negligible.

\section{Miners}

A total of 76 miners were tested at the Birmingham Eye Hospital in the following groups:-

Group (a) certified cases showing active nystagmus $\ldots \quad 17$

Group (b) certified cases showing no active nystagmus 22

Group $(c)$ not certified, but exhibiting active nystagmus 4

Group (d) not certified, and showing no active $\begin{array}{llll}\text { nystagmus, but suspected early cases } & \ldots & 6\end{array}$

Group (e) not certified and showing no nystagmus or $\begin{array}{llll}\text { other symptoms (control group) } & \ldots & \ldots & 27\end{array}$

\section{Total Subjects 76}

Most of the men came from pits in the Coventry and Warwickshire areas. They had been under observation by Dr. Dorothy Campbell at Coventry or Birmingham and the classification for each case was decided by her. In the case of those men certified for nystagmus, periods varying from months to years had elapsed between certification and date of dark adaptation test. The results of the dark adapted threshold are given below.

TABLE III. Miners

\begin{tabular}{|c|c|c|c|c|c|c|}
\hline Group & $\begin{array}{c}\text { Number } \\
\text { in } \\
\text { group }\end{array}$ & $\begin{array}{c}\text { Number } \\
\text { effectively } \\
\text { tested }\end{array}$ & $\begin{array}{c}\text { Average } \\
\text { age }\end{array}$ & \multicolumn{2}{|c|}{$\begin{array}{c}\text { Dark } \\
\text { adaptation } \\
\text { mean (after } \\
\text { individual } \\
\text { correction for } \\
40 / 50 \text { age } \\
\text { group }\end{array}$} & $\begin{array}{l}\text { Standard } \\
\text { deviation }\end{array}$ \\
\hline (a) & 17 & 15 & $47^{\circ} 2$ & \multicolumn{2}{|c|}{$2 \cdot 30 \log \mu \mu 1$} & 0.25 \\
\hline (b) & 22 & $21^{\circ}$ & $49^{\circ} 0$ & 2556 & , & 0.52 \\
\hline (c) & 4 & 4 & 48.5 & 2.56 & , & $0^{\circ} 24$ \\
\hline$(d)$ & 6 & 6 & $43^{\circ} 8$ & $2 \cdot 32$ & , & 0.59 \\
\hline$(e)$ & 27 & 27 & $44^{\circ} 8$ & $2 \cdot 34$ & " & 0.44 \\
\hline
\end{tabular}


The threshold figures shown are each directly comparable with The figure of 2.07 $\log \mu \mu$ l given in Table I for normals (non-miners) in the $40 / 50$ age group. As such a large proportion of the miners tested fell into this age group it was decided to adjust all results to this basis. This was done for the individual results of all miners falling in other age groups by adding to or subtracting from the actual test result the difference between the mean value for normals (non-miners) in the $40 / 50$ age group, viz. $2.07 \log \mu \mu \mathrm{l}$, and the mean value of normals for the age group into which each individual miner fell. Thus a miner of 34 years of age who gave a result of $2 \cdot 11 \log \mu \mu 1$ was entered as having an adjusted value of $2 \cdot 24 \log \mu \mu 1$ in the $40 / 50$ age group, since the mean value of normals (Table I) for the $40 / 50$ age group (2.07 $\log \mu \mu 1)$ is $0.13 \log \mu \mu 1$ higher than the mean value for normals in the $30 / 40$ age group $(1.94 \log \mu \mu 1)$. The mean value shown for each group $(a)$ to $(e)$ is the average of the individually adjusted values.

\section{Observations}

It will be seen that the threshold value in each group $(a)$ to $(e)$ is substantially higher than for the normal $2.07 \log \mu \mu \mathrm{l})$. This is particularly of interest in the case of group (e), miners who show no evidence of the disease, either in respect of eye movements or other symptoms. Practically all these men, however, were obtained for test by reason of their having been at one time or another Eye Hospital patients who had reported an account of minor eye injuries or defective sight.

No discussion of the significance of the results is being attempted here as this is being dealt with by Dr. Dorothy Campbell elsewhere in this issue, in the light of a full series of other tests on the same men.

\section{REFERENCES}

1. WEEKERS, L.-Recherches au suject de l'adaptation des nystagmiques Scalpel, Vol. LXII, p. 213, 1909.

2. Percival, A. S.-Light sense. Trans. Ophthal. Soc, U.K., Vol. XL, p. 311. 1920.

3. Medical Research Council. First report of the Miners' Nystagmus Committee. p. 18,1922 .

4. Coulter, R. J.-The light sense in Miners' Nystagmus. Brit. Med. Jl., (ii), p. $929,1928$.

5. Verhage, J. W. C.-Bergmannystagmus und Adaptationsstörungen. Ophthalmologica, Vol. XCIX, p. 503, 1940.

6. Hecht, S., Shlaer S. and Pirenne, M. W.-Energy, quanta and vision, Jl. Gen. Physiol., Vol. XXV, p. 819, 1942. 